\title{
The evolution of cognitive-behavioral therapy for psychosis
}

\section{Helen Mander \\ David Kingdon}

Mental Health Group, University of Southampton, Southampton,

Hampshire, England, UK
Correspondence: David Kingdon University of Southampton, College Keep, 4- 12 Terminus Terrace, Southampton SOI4 3DT, Hampshire, England, UK Email dgk@soton.ac.uk
This article was published in the following Dove Press journal:

Psychology Research and Behavior Management

18 February 2015

Number of times this article has been viewed
Abstract: Cognitive therapy for psychosis has developed over the past 30 years from initial case studies, treatment manuals, pilot randomized controlled studies to fully powered and methodologically rigorous efficacy and, subsequently, effectiveness trials. Reviews and metaanalyses have confirmed the benefits of the interventions. Considered appraisal by government and professional organizations has now led to its inclusion in international treatment guidelines for schizophrenia. Patients consistently ask for access to psychotherapeutic interventions, and it is slowly becoming available in many European countries and other parts of the world, eg, US and the People's Republic of China. However, it remains unacceptably difficult to access for the vast majority of people with psychosis who could benefit from it. Psychosis affects people in the prime of their lives and leads to major effects on their levels of distress, well-being, and functioning, and also results in major costs to society. Providing effective interventions at an early stage has the potential to reduce the high relapse rates that occur after recovery from first episode and the ensuing morbidity and premature mortality associated with psychosis.

Keywords: psychosis, schizophrenia, psychotherapy, cognitive therapy, history

\section{Introduction}

This paper will begin by presenting a history of psychosis, describing changing explanations of its causality and treatment. After a brief introduction of cognitive-behavioral therapy (CBT), it will provide an overview of CBT as applied to psychosis. An account will be presented of the evolution of CBT for psychosis over the last 30 years, concluding with an overview of current and future research directions.

\section{History of psychosis, causality, and treatment}

Prior to the 19th century, few accounts of psychosis were described in medical or psychiatric literature. Descriptions of disorganized behavior were more likely to be reported with religious or moral explanations. As such, the response to such behavior was likely to be based on the use of behavioral control or moral education.

The recognition of psychotic difficulties by medical establishment appeared around the turn of the 20th century. It was assumed that psychotic symptoms stemmed from a physical origin; however, in the absence of a specific account of how psychosis developed, categorization was created based on perceived similarity of observed symptoms. The term "group of schizophrenias" was first used by the Swiss psychiatrist Bleuler (1908; cited in Kuhn and Cahn). ${ }^{1}$ Derived from Greek roots "skhizein" (split) and "phrene" (mind), this term grouped a range of symptoms associated with separated or fragmented thinking, previously referred to as "dementia praecox" (early dementia) 
by Emile Kraeplin. ${ }^{2}$ The very language used to describe this range of symptoms suggested incomprehensibility.

While Bleuler did consider psychological factors, Jaspers $^{3}$ conceptualized beliefs in schizophrenia as being "nonunderstandable", and this view predominated for most of the 20th century. Treatments developed were based on those used in physical illnesses - symptom reduction was pursued through hospitalization and a range of regimens including various medications and electroconvulsive therapy. In the 1950s, antipsychotic medication was introduced with the introduction of chlorpromazine, which reduced acute symptoms but was less effective in producing change in functioning. Early medication suffered from side effects but allowed a reduction of physical restraints and reliance on long-term hospitalization. However, the impact of societal changes after the Second World War was probably the most important factor in the latter as reductions in hospital numbers preceded this introduction in some enlightened areas, eg, Nottingham, and was long delayed in others, eg, the Far East, despite medication usage.

Psychological explanations were introduced by some psychoanalysts around the same time. Contrasting with the Jasperian approach, theorists gave full attention to the content of the thinking and distress, under the assumption that "all manifestations of the human mind are potentially meaningful". ${ }^{4}$ The therapeutic goals of insight and understanding were approached using talking treatment. However, the attribution of cause to early upbringing and rejection, and in particular the description of the "schizophrenogenic mother", caused damage and alienated many.

Nonunderstandability was challenged by Laing, ${ }^{5}$ who considered psychotic behavior as a potentially understandable symbolic expression of distress of a self within a social cradle. Psychiatry continued to question the validity of schizophrenia as a diagnostic entity. ${ }^{5}$

Psychological approaches as recent as the 1980s used behavioral principles to describe behavioral "excesses," "deficits", and "assets". Describing treatment as taking place largely in hospitals, hostels, or community settings, psychological services were developed to modify behavior, promoting engagement and helpful activities, social skills, and family work. Hall ${ }^{6}$ described the use of functional analysis and identification of therapeutic goals - largely focusing on reducing unacceptable or challenging behaviors, and designing treatment programs based on the principles of operant conditioning, to be carried out through team and family settings.

Throughout history, psychosis (equating to "the group of schizophrenias" as opposed to psychotic symptoms which can occur in a range of conditions) has been generally seen to have biological causes, but increasingly the evidence for psychological, social, and environmental causes has emerged. Influences on observable symptoms, inferred processes, social context, and learning processes have been described which have implications not only for the suggested treatment but also for the concept of psychosis itself.

The current understanding of the causes and development of psychosis aims to accommodate different sources of information within a biopsychosocial framework. This stress-vulnerability approach was made popular by Zubin and Spring. ${ }^{7}$

Regarding a biological influence, a vulnerability to develop psychosis has been shown to be, to some extent, inherited with a role for genetics, although this may be mediated through temperament and personality. Observations of reductions in the size of some brain structures and functional differences in brain activity have been consistently illustrated in individuals with psychotic symptoms, although their significance has been disputed. The role of illicit drugs and trauma in contributing to the onset and development is now widely accepted. ${ }^{8}$

Cognitive factors have also been considered to contribute to the formation of positive symptoms of psychosis. It has been conceptualized that sensory input does not appropriately activate stored expectations, leading to different information processing. ${ }^{9}$ A range of reasoning and attributional biases have been described in individuals with psychosis, including an increased susceptibility to jump to conclusions with limited evidence, and a lower belief flexibility. ${ }^{10}$ People experiencing psychosis are more likely to show a personalizing, external attribution style ${ }^{11}$ and have poor working memory. $^{12}$

Social and environmental factors are also important in the development, onset, and course of psychotic symptoms. An increased risk of developing psychosis is associated with living in an urban environment ${ }^{13}$ and social isolation through immigration. ${ }^{14}$ The role of trauma in the onset of psychosis is widely accepted. Traumatic events are very common, ${ }^{15}$ as are victimization and bullying. ${ }^{16}$ Social deprivation and experiencing racism are associated with paranoid thinking. ${ }^{17}$ Life events predict onset, increased symptomatology, and relapse, mediated by appraisals of situations of low control and poor handling. ${ }^{18}$

In light of this broader framework of understanding psychosis, the relevance and validity of the term "schizophrenia" have continued to be questioned. ${ }^{19}$ In view of a more comprehensive comprehension of a range of causes, some authors 
have called for a range of descriptive labels which incorporate more useful information regarding the causes and nature of symptoms. ${ }^{20}$ However, the current multidimensional understanding has led to developments in treatment, such as a multimodality recovery-focused approach, including medication, psychosocial interventions, and community support.

\section{Cognitive-behavioral therapy}

CBT developed from behavioral approaches (ie, Skinner) ${ }^{21}$ and cognitive-behavior analysis (Ellis). ${ }^{22}$ Beck et al ${ }^{23}$ developed a general theory of emotional disorders. A cognitivebehavioral approach to emotional difficulties assumes that the way that an individual makes sense of an event, rather than the event per se, will determine their experience of that event. On the basis of early experiences, people develop beliefs about their world. Once formed, these beliefs will be stored to form a relatively stable framework, which will then influence the way that new information is interpreted. New information observed from the environment will be interpreted within the guidelines of this framework, or schema. The interpretations of that event then will lead to emotional and behavioral consequences. Events that are interpreted as threatening will lead to responses characterized by anxiety, and are likely to lead to actively avoidant behavior, whereas those interpretations that are associated with loss will lead to sadness and depression and be more likely to lead to withdrawal.

Once distressing responses are triggered, a range of emotional, somatic, and behavioral outcomes may then unfortunately and unintentionally serve to reinforce the unhelpful interpretation. For example, heightened physiological responses to a feared stimulus may unintentionally increase the beliefs around the danger of that stimulus, whereas active avoidance of a stimulus reduces the potential for opportunities to update information around the perceived fear. ${ }^{24}$

Emotional difficulties are presumed to occur when an individual's interpretation of an event is disproportionate with its actual threat. For example, fear and avoidance reflect normal, healthy, and evolutionarily adaptive responses when faced with acute danger. However, the same responses in the absence of danger may be considered unhelpful when they cause distress and interfere with an individual's functioning.

CBT then aims to support an individual in reducing their level of distress by recognizing and modifying their unhelpful interpretations, along with any unhelpful maintaining factors. A wealth of research and clinical experience has led to the development of effective CBTs for a range of emotional difficulties, including anxiety disorders, ${ }^{25}$ unipolar $^{26}$ and bipolar depression, ${ }^{27}$ eating disorders, ${ }^{28}$ and medically unexplained symptoms. ${ }^{29}$

Although a range of different therapies exist under the umbrella of CBT, they all have slightly different accents and characteristics. However, CBTs are united by certain principles. These include those concerned with theory (CBT is empirically based, and is driven by an explicit and testable conceptualization of predisposing, precipitating, presenting, maintaining, and protective factors), application (CBT is change focused, goal directed, time-limited), and process (CBT is used within a collaborative therapeutic relationship).

\section{Cognitive-behavioral therapy for psychosis}

Consistent with general cognitive-behavioral theory, CBT for psychosis is based on the assumption that distress occurs when an individual makes sense of his or her experiences in a threatening way. Although different theorists will emphasize different aspects and strategies, cognitive models of psychosis feature the underlying agreement.

\section{Beliefs in psychosis are important, comprehensible, and modifiable}

In contrast to historical theorists who viewed delusions as "psychologically ununderstandable", ${ }^{3}$ CBT suggests that delusions can be seen as a way to make sense of anomalous experiences. ${ }^{30}$ When the interpretation of these anomalous events is a threatening and culturally unacceptable one, this interpretation leads to distress. Brett et $\mathrm{al}^{31}$ showed that the nature of people's beliefs about threat from voices is a stronger predictor of distress and response than voice severity. Rather than being ununderstandable, beliefs in psychosis often reflect personal histories ${ }^{32}$ and so are meaningful in the context of anomalous/life experiences. Although these beliefs show lower levels of flexibility in comparison with the general population, ${ }^{10}$ they fluctuate on a continuum with normal beliefs and are not necessarily held with absolute certainty, and conviction fluctuates over time..$^{33}$ Beliefs can be amenable to reason. ${ }^{34}$ These factors will influence formation of beliefs about anomalous experiences. People with delusions tend to have no alternative for their explanation for experiences. ${ }^{35}$

\section{Experiences in psychosis are on a continuum with those in the general population}

Rather than a distinction between "normal" and "abnormal" experiences and beliefs, CBT emphasizes the continuation of experiences within the whole population. Beliefs that may 
appear unusual or unfounded, including those concerned with persecution or conspiracy, are common in the general population. ${ }^{36}$ Beliefs based on "sketchy" evidence are prevalent ${ }^{37}$ and subject to the same confirmation and thinking biases as are seen for all beliefs. Seeing or hearing things in the absence of external stimuli is also far from unusual in the general population - eg, $25 \%-40 \%$ of people in the general population hear voices, often associated with stress, loss, isolation, etc, and this is not necessarily associated with distress ${ }^{38}$ - and a normal experience, given the right (or the wrong) conditions, including sleep or sensory deprivation and drug use.

\section{Therapeutic efforts should be aimed at reducing distress and increasing well-being}

In contrast to medical focus on psychotic symptom reduction, cognitive-behavioral approaches are directed toward decreasing distress and increasing well-being. This approach will be guided by the individual and his or her current difficulties and priorities. As discussed earlier, beliefs around experiences are better able to account for distress than the experiences alone; therefore, CBT may involve formulating and developing alternative beliefs around an individual's anomalous experiences. When people suffer distress after an experience, they are likely to engage in somatic, cognitive, and behavioral attempts to reduce that experience. These attempts can unintentionally maintain the interpretations and distress, and can also become problematic and limit wellbeing themselves. Therapeutic endeavors may be directed toward identifying and modifying these maladaptive strategies, and developing more helpful alternatives. People with severe and enduring mental health difficulties are more likely to experience a range of concurrent difficulties, including being more likely to suffer adverse life situations, poor physical health outcomes, drug use, and social exclusion. ${ }^{39}$ The levels of depression and anxiety are high for people with psychosis, ie, $25 \%$ with OCD and $20 \%$ with panic disorder. ${ }^{40}$ CBT may therefore focus on a range of difficulties using assessment, formulation, validating, normalizing, and assisting generation of more helpful and plausible explanations to explain experiences.

\section{The evolution of CBT for psychosis}

Aaron Beck, while still working psychoanalytically, initially used a psychotherapeutic approach to delusional guilt in chronic schizophrenia ${ }^{41}$ before moving his focus of attention toward explanations for depression and anxiety, leaving psychosis neglected by cognitive therapists for many years. Some case descriptions of broadly cognitive-behavioral approaches were published in the 1980 s. $^{6}$ However, this appeared more closely related to a behavior and contingency modification program as used in other long-stay inpatient settings as opposed to the talking therapies that were gathering support in addressing depression and anxiety.

The recent reemergence of CBT for psychosis came from a number of researchers working independently in the 1980s. Tarrier et $\mathrm{al}^{42}$ developed coping strategy enhancement. It has been found that individuals experiencing distressing voices practice coping strategies inconsistently and poorly; hence, coping strategy enhancement involves using behavioral analysis to assess frequency, intensity, duration, and onset of each symptom. Subsequently, it was investigated how the client employs coping strategies in response to the emotional, physical, cognitive, and behavioral distress. These attempts at coping are categorized as appropriate or inappropriate depending on the benefits and detriment they cause. Tarrier et $\mathrm{al}^{42}$ taught clients to monitor illness phenomena and use relaxation techniques "in vivo" as well as other distraction, self-talk, or coping strategies.

Often eliciting the client's explanations for the cause of their symptoms can be an opportunity to normalize their experiences. Kingdon and Turkington's ${ }^{43}$ stress-vulnerability conceptualization was central to the development of a full cognitive model of psychosis, along with strong emphasis on engagement and psychoeducation. This model led to suggestions for the use of cognitive techniques for addressing delusions, hallucinations, and disordered thinking, within a case formulation approach.

Over the last 20 years, a number of authors and clinicians have contributed to a range of cognitive and behavioral models to account for the development and maintenance of psychosis (Bentall, ${ }^{44}$ Fowler et al, ${ }^{45}$ Chadwick and Birchwood, ${ }^{46}$ Freeman and Garety, ${ }^{47}$ Gumley and Power, ${ }^{48}$ and Morrison et $\left.\mathrm{al}^{49}\right)$. The ongoing skepticism around the concept of schizophrenia led to the generation of a range of symptom-focused models: eg, cognitive models of delusions, ${ }^{10}$ voices,${ }^{50}$ and command hallucinations. ${ }^{51}$

Since the turn of the new century, cognitive models for psychosis have been influenced in parallel to advances taking place in the treatment of affective disorders, learning from these established models. Third-wave approaches are based on the assumption that it is possible to take a metacognitive perspective on internal and external experiences. In his personbased cognitive therapy for distressing psychosis, and moving from a symptom-based understanding to a person-based understanding, Chadwick ${ }^{52}$ updates previous symptom-based 
understanding by increasing the focus on the importance of the therapeutic relationship, using Vygotsky's zone of proximal development as a framework and including specific focus on mindfulness, metacognition, and work on the self.

Another strand of cognitive therapy focused on processes that were observed to be heightened in psychosis. For example, Freeman et $\mathrm{al}^{53}$ observed that clients experiencing paranoia displayed worry to a level comparable with those diagnosed with generalized anxiety disorder. In line with the generalized anxiety disorder literature, they are exploring the role of a metacognitive-process-based therapy for worry in paranoia.

Based on the observations outlined earlier that people experiencing distress and continuing to experience psychotic symptoms are more likely to experience a range of cognitive features, some effective therapy had been developed by metacognitive training designed to address these tendencies explicitly.

Short-term treatments are important to direct health resources where they are most effective. In the wake of the huge investments made to Increasing Access to Psychological Therapies Services in the United Kingdom over the last few years, attention has now been adjusted to consider proving evidence-based short-term or "low intensity" psychological interventions for adults with severe and enduring mental health difficulties to improve implementation. ${ }^{54}$ Research is also directed at the development of training and supervision for therapists in this area. ${ }^{55}$

At this stage in the CBT for psychosis, a number of meta-analyses have been carried out, which have shown an overall modest effect of CBT on positive symptoms of psychosis, ${ }^{56}$ especially for persistent symptoms, ${ }^{57}$ although some wide-ranging meta-analyses have questioned this. ${ }^{58,59}$ This has been fully explored elsewhere. ${ }^{60}$

In other areas, evidence is currently emerging, with incomplete but potentially promising support for CBT in early intervention, ${ }^{61}$ which may provide some benefit in symptom reduction, adaptation to illness, and subjective quality of life, although there is limited evidence for a reduction in hospitalization or relapse. ${ }^{62}$ Similarly, evaluations of CBT for people at high risk of developing psychosis are in their infancy, ${ }^{63}$ although appearing to be promising in reducing at-risk symptoms, and require further exploration. With the incomplete effects of antipsychotic medication, a recent study has suggested that CBT can be effective for people who choose not to take antipsychotic medication. ${ }^{64}$

It has been an exciting time for CBT for psychosis, with many questions still requiring further study. Developing a culturally acceptable CBT has received some attention, ${ }^{65}$ but more needs to be done. There has been very little research with under 18 and over 65 year old clients or with forensic populations. After a long history of neglect, psychological therapy for psychosis has begun to receive the attention it deserves and is now included in most national clinical guidelines for management of psychosis. Research is flourishing, and refinements of the broad intervention are being developed with a focus on specific targets such as worry, sleep, and depression within the broad syndrome.

\section{Disclosure}

Professor Kingdon receives grants and royalties from published books about cognitive therapy for research purposes. The authors report no other conflicts of interest in this work.

\section{References}

1. Kuhn R, Cahn CH. Eugen Bleuler's concepts of psychopathology. Hist Psychiatry. 2004;15:361-366.

2. Engstrom EJ, Weber MM. The Directions of psychiatric research by Emil Kraepelin. Hist Psychiatry. 1887;16(63 Pt 3):345-364.

3. Jaspers K. Allgemeine Psychopathologie. Berlin, Germany: Springer; 1913.

4. Fromm-Reichmann F. Notes on the development of treatment of schizophrenia by psychoanalytic therapy. Psychiatry. 1948;11:263-273.

5. Laing RD. The Divided Self: An Existential Study in Sanity and Madness. Harmondsworth: Penguin; 1960.

6. Hall J. Chronic psychiatric handicaps. In: Hawton K, Paul M, Salkovskis JK, Clark DM, editors. Cognitive Behaviour Therapy for Psychiatric Problems. Oxford University Press, UK: Oxford; 1989.

7. Zubin J, Spring B. Vulnerability: a new view of schizophrenia. JAbnorm Psychol. 1977;86:103-126.

8. Kuepper R, van Os J, Lieb R, Wittchen H, Hofler M, Henquet C. Continued cannabis use and risk of incidence and persistence of psychotic symptoms: 10 year follow-up cohort study. $\mathrm{Br}$ Med $J$. 2011;342:d738.

9. Hemsley D. The development of a cognitive model of schizophrenia: placing it in context. Neurosci Biobehav Rev. 2005;29:977-988.

10. Garety PA, Kuipers E, Fowler D, et al. A cognitive model of the positive symptoms of psychosis. Psychol Med. 2001;31:189-195.

11. Kinderman P, Bentall RP. Causal attributions in paranoia and depression: internal, personal, and situational attributions for negative events. J Abnorm Psychol. 1997;106:341-345.

12. Lee J, Park S. Working memory impairments in schizophrenia: a metaanalysis. J Abnorm Psychol. 2005;114:599-611.

13. Sundquist K, Frank G, Sundquist J. Urbanisation and incidence of psychosis and depression: follow-up study of 4.4 million women and men in Sweden. Br J Psychiatry. 2004;184:293-298.

14. Veling W, Susser E, van Os J, Mackenbach JP, Selten JP, Hoek HW. Ethnic density of neighbourhoods and incidence of psychotic disorders among immigrants. Am J Psychol. 2008;165:66-73.

15. Resnick SG, Bond GR, Mueser KT. Trauma and posttraumatic stress disorder in people with schizophrenia. J Abnorm Psychol. 2003;112: 415-423.

16. Bebbington PE, Bhugra D, Brugha T, et al. Psychosis, victimisation and childhood disadvantage: evidence from the British National Survey of Psychiatric Morbidity. Br J Psychiatry. 2004;185:220-226.

17. Mirowsky J, Ross CE. Paranoia and the structure of powerlessness. Am Sociol Rev. 1983;48:228-239. 
18. Horan WP, Venture J, Nuechterlein KH, Subotnik KL, Hwang SS, Mintz J. Stressful life events in recent-onset schizophrenia: reduced frequencies and altered subjective appraisals. Schizophr Res. 2005;75: 363-374.

19. Allardyce J, Gaebel W, Zielasek W, van Os J. Deconstructing Psychosis Conference February 2006: the validity of schizophrenia and alternative approaches to the classification of psychosis. Schizophr Bull. 2007;33:863-867.

20. Kingdon D. Down with schizophrenia. New Scientist. October 17, 2007.

21. Skinner BF. About Behaviorism. New York, NY: Vintage; 1974.

22. Ellis A. Reason and Emotion in Psychotherapy. New York, NY: Lyle Stewart; 1962.

23. Beck AT. Cognitive Therapy and the Emotional Disorders. Ann Arbor, MI: International Universities Press; 1976.

24. Salkovskis P, Hackman A, Wells A, Gelder MG, Clark DM. Belief disconfirmation versus habituation approaches to situational exposure in panic disorder with agoraphobia: a pilot study. Behav Res Ther. 2007;45:877-885.

25. Butler AC, Chapman JE, Forman EM, Beck AT. The empirical status of cognitive-behavioral therapy: a review of meta-analyses. Clin Psychol Rev. 2006;26:17-31.

26. Paykel ES, Scott J, Teasdale J, et al. Prevention of relapse in residual depression by cognitive therapy: a controlled trial. Arch Gen Psychiatry. 1999;56:829-835.

27. Scott J, Paykel E, Morriss R, et al. Cognitive-behavioural therapy for severe and recurrent bipolar disorders: randomised controlled trial. Br J Psychiatry. 2006;188:313-320.

28. Agras WS, Walsh BT, Fairburn CG, Wilson GT, Kraemer HC. A multicenter comparison of cognitive-behavioural therapy and interpersonal psychotherapy for bulimia nervosa. Arch Gen Psychiatry. 2000;57:459-466.

29. Malouff J, Thorsteinsson E, Rooke S, Bhullar N, Schutte N. Efficacy of cognitive behavioural therapy for chronic fatigue syndrome: a metaanalysis. Clin Psychol Rev. 2008;28:736-745.

30. Maher B. Anomalous experience and delusional thinking: the logic of explanations. In: Oltmanns TF, Maher BA, editors. Delusional Beliefs. Chichester, England: Wiley; 1988:15-33.

31. Brett CM, Johns LC, Peters EP, McGuire PK. The role of metacognitive beliefs in determining the impact of anomalous experiences: a comparison of help-seeking and non-help-seeking groups of people experiencing psychotic-like anomalies. Psychol Med. 2009;39: 939-950.

32. Johns LC, Cannon M, Singleton N, et al. Prevalence and correlates of self-reported psychotic symptoms in the British population. Br J Psychiatry. 2004;185:298-305.

33. Sharp HM, Fear CF, Williams JMG, et al. Delusional phenomenologydimensions of change. Behav Res Ther. 1996;34:123-142.

34. Kuipers E, Garety PA, Fowler D, et al. London-East Anglia randomised controlled trial of cognitive-behaviour therapy for psychosis. I: effects of the treatment phase. Br J Psychiatry. 1997;171:319-327.

35. Freeman D, Garety PA, Fowler D, Kuipers E, Bebbington P, Dunn G. Why do people with delusions fail to choose more realistic explanations for their experiences? An empirical investigation. J Consult Clin Psychol. 2004;72:671-680.

36. Peters E, Joseph S, Day S, Garety P. Measuring delusional ideation: the 21-item Peters et al. Delusions Inventory (PDI). Schizophr Bull. 2004;30:1005-1022.

37. Hemsley DR, Garety PA. The formation of maintenance of delusions: a Bayesian analysis. Br J Psychiatry. 1986;149:51-56.

38. Romme M, Escher S. Hearing voices. Schizophr Bull. 1989;15: 209-216.

39. Roberts L, Roaslfe A, Wilson S, Lester H. Physical health care of patients with schizophrenia in primary care: a comparative study. Fam Pract. 2007;24:34-40.

40. Turnbull G, Bebbington P. Anxiety and the schizophrenic process: clinical and epidemiological evidence. Soc Psychiatry Psychiatr Epidemiol. 2001;36(5):235-243.
41. Beck AT. Successful outpatient psychotherapy of a chronic schizophrenic with a delusion based on borrowed guilt. Psychiatry. 1952;15: 305-312.

42. Tarrier N, Harwood S, Yusupoff L, Beckett R, Baker A. Coping strategy enhancement (CSE): A method of treating residual schizophrenic symptoms. Behav Psychother. 1990;18:283-293.

43. Kingdon D, Turkington D. Cognitive Behaviour Therapy of Schizophrenia. New York, NY: Guildford Press; 1994.

44. Bentall RP. The illusion of reality: a review and integration of psychological research on hallucinations. Psychol Bull. 1990;107(1):82-95.

45. Fowler D, Garety PA, Kuipers L. Cognitive Behaviour Therapy for Psychosis: Theory and Practice. Chichester, England: Wiley; 1995.

46. Chadwick PDJ, Birchwood MJ. The omnipotence of voices: a cognitive approach to hallucinations. Br J Psychiatry. 1994;164:190-201.

47. Freeman D, Garety PA. Worry, worry processes and dimensions of delusions: an exploratory investigation of a role for anxiety processes in the maintenance of delusional distress. Behav Cogn Psychother. 1999;27:47-62.

48. Gumley AI, Power KG. Is targeting cognitive therapy during relapse in psychosis feasible? Behav Cogn Psychother. 2000;28:161-174.

49. Morrison AP, Renton JC, Dunn H, Williams S, Bentall RP. Cognitive Therapy for Psychosis: A Formulation-Based Approach. Brigton, NY: Psychology Press; 2003.

50. Morrison AP. Cognitive therapy for auditory hallucinations: a theorybased approach. Cogn Behav Pract. 2001;8:147-160.

51. Byrne S, Birchwood M, Trower PE, Meaden A. A Casebook of Cognitive Behaviour Therapy for Command Hallucinations: A Social Rank Theory Approach. New York, NY: Routledge; 2007.

52. Chadwick PDJ. Person-Based Cognitive Therapy for Distressing Psychosis. Chichester. England: Wiley; 2006.

53. Foster C, Startup H, Potts L, Freeman D. A randomised controlled trial of a worry intervention for individuals with persistent persecutory delusions. J Behav Ther Exp Psychiatry. 2010;41:45-51.

54. Waller H, Garety P, Jolley S, et al. Training Frontline Mental Health Staff to deliver "low intensity" psychological therapy for psychosis: a qualitative analysis of therapist and service user views on the therapy and its future implementation. Behav Cogn Psychother. 2013;23: 1-16.

55. Jolley S, Onwumere J, Kuipers E, Craig T, Mariarty A, Garety P. Increasing access to psychological therapies for people with psychosis: predictors of successful training. Behav Res Ther. 2013;50: 457-462.

56. Wykes T, Steel C, Everitt B, Tarrier N. Cognitive behaviour therapy for schizophrenia: effect sizes, clinical models, and methodological rigor. Schizophr Bull. 2008;34:523-537.

57. Burns AM, Erickson DH, Brenner CA. Cognitive-Behavioral Therapy for Medication-Resistant Psychosis: A Meta-Analytic Review. Psychiatr Serv. Epub Apr 12014.

58. Jauhar S, McKenna PJ, Radua J, Fung E, Salvador R, Laws KR. Cognitive-behavioural therapy for the symptoms of schizophrenia: systematic review and meta-analysis with examination of potential bias. Br J Psychiatry. 2014;204:20-29.

59. Institute of Psychiatry. 50th Maudsley Debate: CBT for Psychosis. Available from: http:/www.kcl.ac.uk/ioppn/news/maudsleydebates/ debate-archive-31-50.aspx. Accessed December 19, 2014.

60. World Psychiatry. Forum-promise and limitations of cognitive behavior therapy for severe mental disorders. Available from: http://www. wpanet.org/uploads/Publications/WPA_Journals/World_Psychiatry/ Past_Issues/English/World\%20Psychiatry_October\%202014.pdf. Accessed October 21, 2014

61. Marshall M, Rathbone J. Early intervention for psychosis. Schizophr Bull. 2011;37:1111-1114.

62. Couture SM, Penn DL, Roberts DL. The functional significance of social cognition in schizophrenia: a review. Schizophr Bull. 2006;32: S44-S63.

63. Addington J, Epstein I, Lui L, French P, Boydell KM, Zipursky RB. A randomised controlled trial of cognitive behavioural therapy for individuals at clinical high risk of psychosis. Schizophr Res. 2011;125: 54-61. 
64. Morrison AP, Turkington D, Pyle M, et al. Cognitive therapy for people with schizophrenia spectrum disorders not taking antipsychotic drugs: a single-blind randomised controlled trial. Lancet. 2014;383: 1395-1403.

65. Rathod S, Phiri P, Harris S, et al. Cognitive behaviour therapy for psychosis can be adapted for minority ethnic groups: a randomised controlled trial. Schizophr Res. 2013;143(2-3):319-326.
66. Garety PA, Fowler D, Kuipers E. Cognitive-behavioral therapy for medication-resistant symptoms. Schizophr Bull. 2000;26(1): $73-86$.

\section{Publish your work in this journal}

Psychology Research and Behavior Management is an international, peerreviewed, open access journal focusing on the science of psychology and its application in behavior management to develop improved outcomes in the clinical, educational, sports and business arenas. Specific topics covered include: Neuroscience, memory \& decision making; Behavior modification \& management; Clinical applications; Business \& sports performance management; Social and developmental studies; Animal studies. The manuscript management system is completely online and includes a quick and fair peer-review system. Visit http://www.dovepress. com/testimonials.php to read real quotes from published authors.

Submit your manuscript here: http://www.dovepress.com/psychology-research-and-behavior-management-journal 